\title{
Capacity Analysis and Simulation for Mobile WiMAX System in Distributed Subcarrier Permutation Modes in a Proposed Channel
}

\author{
Safwan E. Abdul Fatah
}

\author{
Dr. Sami A. Mawjoud
}

\begin{abstract}
In this paper, capacity analysis for mobile WiMAX working in distributed subcarrier permutation modes is investigated mathematically depending on the physical layer simulation results. These simulation results of physical layer dispose exact values for the number of best burst profiles that candidate to carry Medium Access Control (MAC) payload in a proposed ITU-R mixed user channel. The complete simulation model for physical and MAC layers has been made using OPNET 14.5 to validate the analytical results of the obtained capacity. This approach for capacity analysis based on simulation results is proposed to overcome the lack of interests by other researches in the significant influence of the physical layer constraints on the MAC layer capacity calculations. As well as in this paper, a proposed ITU-R mixed user channel is performed to suit the high mobility users involved under distributed subcarrier permutation modes. Moreover, this paper focused on the exact overhead calculations by taking into account all the significant overhead parameters in the MAC layer frame structure that affects the overall system capacity.
\end{abstract}

Keywords

IEEE802.16e-2005, OFDMA, PUSC, FUSC, QoS, proposed ITU-R mixed user channel model, PER.

$$
\text { تحليل ومحاكاة السعة لنظام الواي ماكس المتنقل لتباديل الحاملات الفرعية الموزعة في }
$$

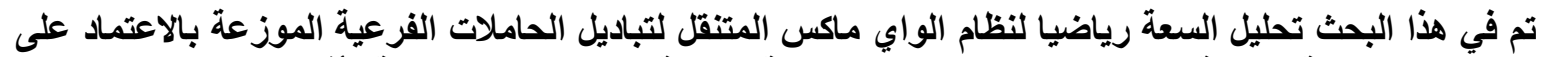

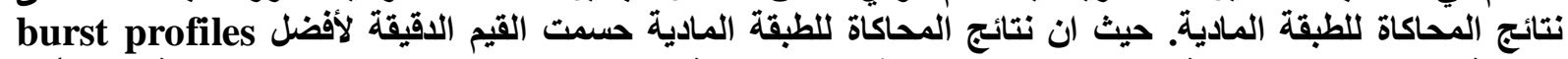

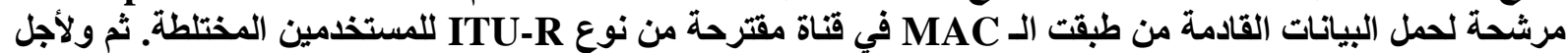

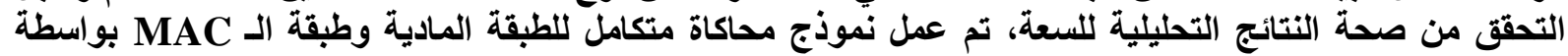

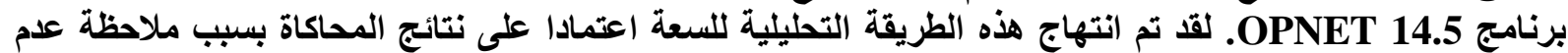

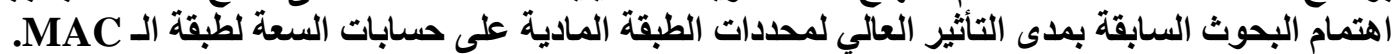

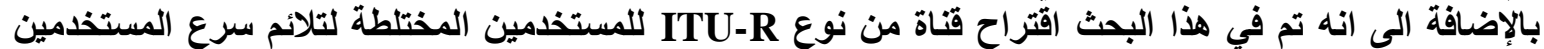

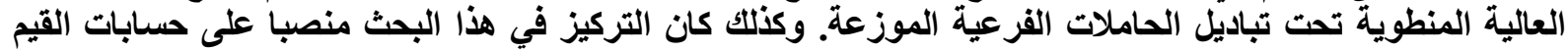

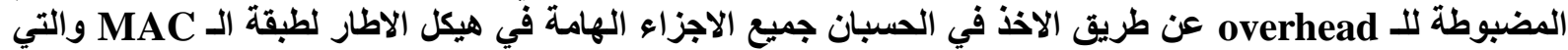
يتألف منها الـ overhead و التي تكون ذات تأثير على سعة النظام الكلية. 


\section{Introduction:}

The mobile WiMAX physical layer implements Orthogonal Frequency Division Multiple Access (OFDMA) for improved multi-path performance in Non-Line-of-Sight (NLOS) environments by converting the wide band frequency selective fading channel into a set of flat fading subchannels. OFDMA is a flexible multiple-access technique that can accommodates many users with widely versatile applications, data rates, and Quality of Services (QoS) requirements [1]. Scalable OFDMA (SOFDMA) [2] is introduced in the IEEE 802.16e-2005 amendment to support scalable channel bandwidths (typically $1.25 \mathrm{MHz}, 5 \mathrm{MHz}, 10 \mathrm{MHz}$ or $20 \mathrm{MHz}$ ). The scalability is supported by scaling the Fast Fourier Transform (FFT) size to the channel bandwidth in order to fix the subcarrier frequency spacing at $10.94 \mathrm{kHz}[3]$. Moreover, in the digital implementation of SOFDMA, the ISI can be completely eliminated through the use of a Cyclic Prefix (CP) [1].

The multiuser diversity and Adaptive Modulation and Coding (AMC) principles are used to enhance the performance of the OFDMA technique. Multiuser diversity describes the gains available by selecting a user or sub-set of users having good channel conditions. AMC is the means by which good channels can be exploited to achieve higher data rates [1].

The Mobile Stations (MSs) estimate and feedback the Channel State Information (CSI) to the centralized Base Station (BS), where subcarrier and power allocation are determined according to users' CSI. Once the subcarriers for each MS have been assigned, the BS must inform each MS which subcarriers have been allocated to it. This subcarrier mapping must be broadcast to all MSs using the MAC control messages placed in the beginning of the MAC frame structure. This resource-allocation procedure lies under the tasks of MAC layer, which is also responsible of: establishing connections; resource allocation; ensuring QoS for various applications; fragment, pack or concatenate the Service Data Units (SDUs) received from higher layers into the MAC Protocol Data Units (PDUs) which is the basic building block of MAC layer payload; and selecting the appropriate burst profile and power level to be used for the transmission of MAC PDUs [1, 4, 5].

In this paper, we present DL MAC layer mathematical analysis to calculate the exact (statistic and dynamic) overhead slots, which are used for controlling messages. This is performed by solving the algorithms that manage the assignments slot size, the ordering, and repetition sequence of these messages in the DL distributed subcarrier permutation modes. Then by eliminating the calculated overhead slots, and considering the physical layer simulation results, the system capacity can be calculated in terms of maximum number of users served by the BS for video streaming application. In order to validate the obtained capacity analytical results, a complete simulation model for physical and MAC layers has been carried out under the same analytical and physical model considerations using OPNET 14.5 modular.

However, to the best of our knowledge, all the researchers that dealt with capacity calculation of the mobile WiMAX system, did not consider the actual impact of multipath fading channel impairments on the physical layer performance. They resorts assumptions to facilitate the inherent difficulties and complexities in determining: number, types, and weights of the used MCSs by the BS. These assumptions are considered somewhat far from the essentials that characterized the IEEE 802.16e standard, and may lead to give unrealistic and incomprehensive results for the calculated system capacity, especially when the MSs mobility and the multipath fading effects are discarded by assuming only AWGN channel. 


\section{Physical Layer Model for Mobile WiMAX Transceiver:}

The main functionality of the IEEE 802.16e OFDMA physical layer is to encode the data bits represented by a MAC frame with various signal processing schemes. Also, a more robustness signal against the channel impairments (e.g. noise and fading) can be obtained. Moreover, it is possible to increase link throughput of the system through choosing a proper MCSs (link speeds). At the receiver side, the encoded signal is decoded to obtain the original data bits. By comparing a delayed version of the transmitted data bits with the decoded bits at the receiver side, the Packet Error Rate (PER) in terms of SNR could be evaluated as a part of Link Level Simulation (LLS). The mobile WiMAX physical layer model shown in figure (1) are designed according to the standard documents $[6,7]$.

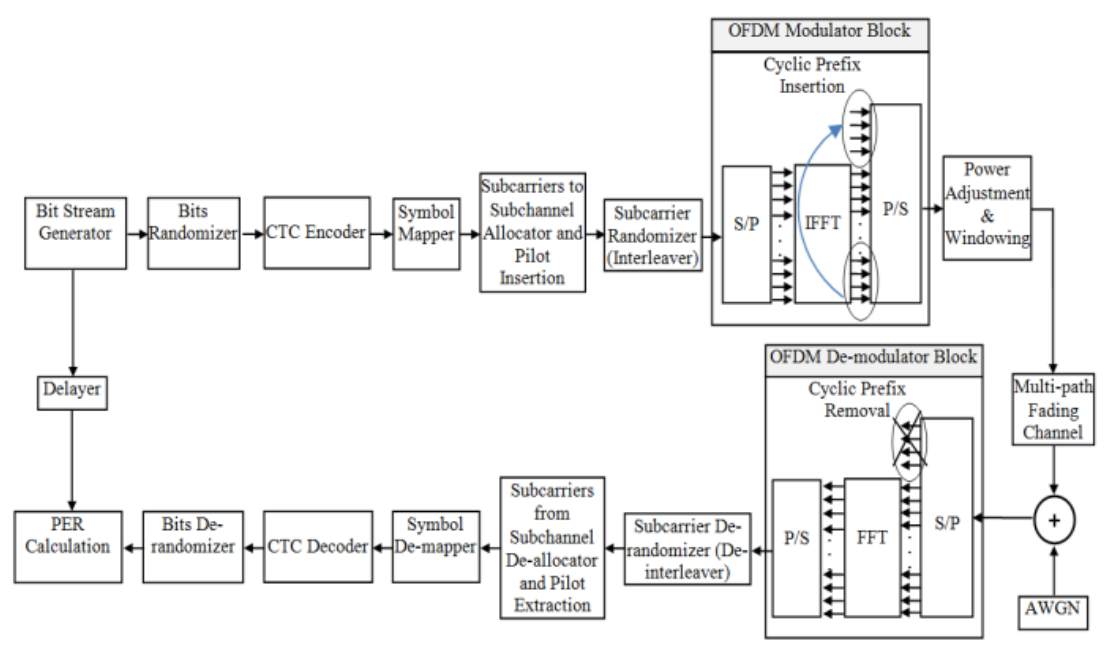

Figure (1): Physical layer model for mobile WiMAX system

\section{Frame Structure and OFDMA Slots:}

The mobile WiMAX supports both Frequency Division Duplexing (FDD) and Time Division Duplexing (TDD) frame structure. Most WiMAX deployments are likely to be in TDD mode due to its flexibility in sharing the asymmetrical data rate between UL and DL subframes especially for applications like web surfing $[1,4,8]$. The TDD frame has a fixed time duration between $2 \mathrm{msec}$ and $20 \mathrm{msec}$ with a static selection. The TDD frame consists of consecutive downlink (DL) and uplink (UL) subframes, which are transmitted on the same carrier frequency at different time separated by a guard periods called Transmit-Receive Transition Gap (TTG) and Receive-Transmit Transition Gap (RTG) as shown in figure (2). Each DL and UL subframe in mobile WiMAX is divided into various zones, each using a different subcarrier permutation mode. The OFDMA frame may include multiple zones. The switching between zones is indicated in the DL-MAP control message. The maximum number of DL zones is eight in one DL subframe. The physical layer parameters may

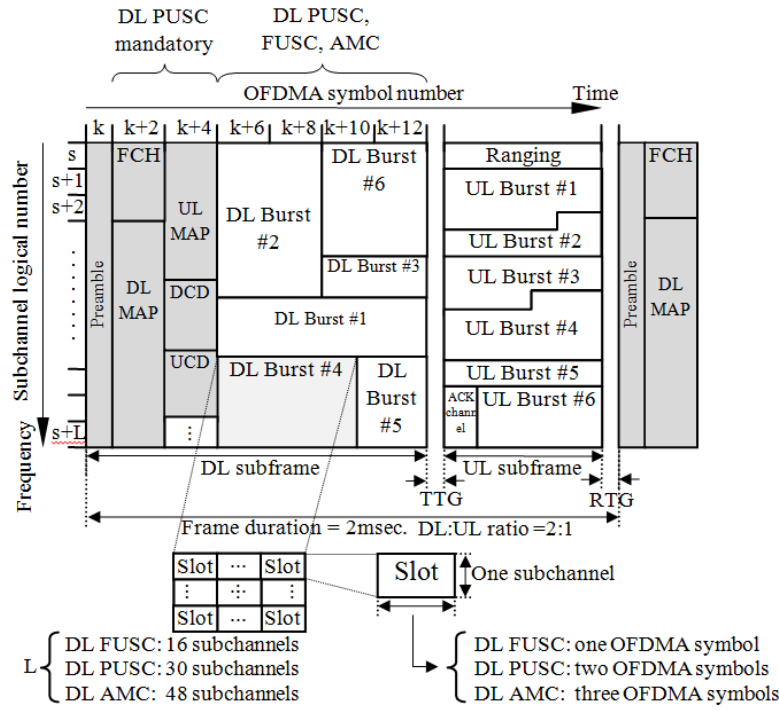

Figure (2): OFDMA TDD frame structure 
change from one zone to the next $[1,4,6,7]$.

The modulated data symbols and pilots are mapped onto subcarriers to form an OFDMA symbol, which is the minimum time resource-unit allocated by the BS. Then a subset of subcarriers are grouped to form a subchannel, which is the minimum frequency resource-unit allocated by the BS. Therefore, different subchannels may be allocated to different users as a multiple-access mechanism [9]. The mapping process to form a subchannel from multiple subcarriers is called permutation, which is basically two types: distributed throughout the frequency band, and adjacent in which each subchannel is constructed by a set of adjacent subcarriers. The mandatory DL distributed subcarrier permutation modes included: Full Usage of the SubChannels (FUSC) and Partial Usage of the SubChannels (PUSC). The mandatory DL adjacent subcarrier permutation mode included: Adaptive Modulation and Coding (AMC). For more details, the mandatory subcarrier permutation modes allowed in IEEE 802.16e-2005 are discussed extensively in [10].

The subchannel with the OFDMA symbols then organizing the OFDMA slot, which is the minimum possible data allocation unit that can be allocated to a single user in the timefrequency domain. The definition of the OFDMA slot differs for DL and UL subframes, and for different subcarrier permutation modes [1,9], see figure (2). Again, the slot is the basic building block to organize the DL and UL data burst. Burst in general terms, is a data region that is a two-dimensional data block consisting of a group of contiguous subchannels by a group of contiguous OFDMA symbols as illustrated in figure (2). To accommodate different users with different modulation and coding schemes, the DL subframe designed to contain several bursts. Each burst is modulated with a different modulation and coding scheme which is called burst profile. Each burst profile then assigned to users located approximately at the same distance from BS. The DL and UL data bursts are of variable rectangular size and carry the PDUs of the MAC layer [8, 9, 10]. The MAC layer assigns data bursts to users to be mapped into the OFDMA frame structure together with the relevant controlling messages overhead with separate time slots to accommodate both DL and UL traffic under consideration of QoS requirements.

This paper focuses on the mandatory distributed subcarrier permutation modes, which are provided frequency diversity gain over the whole frequency band in FUSC and over a part of the frequency band in PUSC. This diversity averaging the effects of interference. Therefore, it can accommodate an environment of high mobility channel condition, even when the quality of each subcarrier steadily varies from one symbol (or frame) to another $[1,9,11]$. The various parameters related to the distributed (PUSC, FUSC) permutation modes with 1024FFT sizes are shown in table (1) [6, 7].

Table (1): 1024-FFT, 10MHz-BW OFDMA PUSC, FUSC subcarrier allocation parameters

\begin{tabular}{|c|c|c|}
\hline Parameters & FUSC & PUSC \\
\hline $\begin{array}{l}\text { Number of Used Subcarriers }\left(\mathrm{N}_{\mathrm{used}}\right) \text { (with pilots and the DC } \\
\text { subcarrier) }\end{array}$ & 851 & 841 \\
\hline Number of data subcarriers $\left(\mathrm{N}_{\text {data }}\right)$ & 768 & 720 \\
\hline Number of pilot Subcarriers & 82 & 120 \\
\hline Number of subchannels $\left(\mathrm{N}_{\mathrm{ch}}\right)$ & 16 & 30 \\
\hline A slot consists of & $\begin{array}{l}\text { 1Subch. } \times 1 \text { OFDMA } \\
\text { sym. }\end{array}$ & $\begin{array}{l}\text { 1Subch. } \times 2 \mathrm{OFD} \\
\text { MA sym. }\end{array}$ \\
\hline Number of data subcarriers in each symbol per subchannel & 48 & 24 \\
\hline Number of data Subcarriers per slot & 48 & 48 \\
\hline
\end{tabular}




\section{The Proposed Mixed User Channel Model:}

We consider empirical channel model that generally used for describing the mobile WiMAX system. This is ITU-R channel model, which was developed according to the ITU-R M.1225 Recommendation [12]. Then adding a white Gaussian noise with a specified noise density to the transmitted signal to simulate the background noise of the channel.

The proposed channel simulation model presented in this paper is more accurate, and approximately near real channel environment by considering high mobility users involved under distributed subcarrier permutation mode. This proposed channel is a modified version of the ITU-R mixed user channel introduced by the WiMAX forum [3, 13]. The modification is based on mixing the vehicular and pedestrian channel with different MSs speeds according to the following weights: ITU Ped. B $(3 \mathrm{~km} / \mathrm{h})$ with a weight of $20 \%$, ITU Veh. A $(30 \mathrm{~km} / \mathrm{h})$ with a weight of $30 \%$, ITU Veh. A $(60 \mathrm{~km} / \mathrm{h})$ with a weight of $40 \%$ and ITU Veh. A (120 $\mathrm{km} / \mathrm{h}$ ) with a weight of $10 \%$. The maximum delay spread for the pedestrian and vehicular channels are $3700 \mathrm{nsec}$ and $2510 \mathrm{nsec}$, respectively. MS is experience to a maximum Doppler spread given as $\mathrm{f}_{\mathrm{D}}=\mathrm{v} \times \mathrm{f}_{\mathrm{c}} / 3 * 10^{8}$, which is equal to $6.38 \mathrm{~Hz}, 63.8 \mathrm{~Hz}, 128 \mathrm{~Hz}$ and $255 \mathrm{~Hz}$ according to the MS velocity (v) of $3 \mathrm{~km} /$ hour, $30 \mathrm{~km} / \mathrm{hour}, 60 \mathrm{~km} / \mathrm{hour}$ and $120 \mathrm{~km} / \mathrm{hour}$, respectively at a carrier frequency $\left(\mathrm{f}_{\mathrm{c}}\right)$ of $2.3 \mathrm{GHz}$.

\section{MAC Layer Overhead Calculations in DL FUSC and PUSC Permutation Modes:}

The most significant overhead parameters affecting the MAC throughput is the control messages overhead, which consists of static part (fixed in size and is not affected by the number of users) overhead and dynamic part (variable in size and is affected by the number of users) overhead and both of them are dealt with in this work.

The control overhead messages are preamble, FCH (Frame Control Header), DL-MAP, UL-MAP, DCD (Downlink Channel Descriptor), and UCD (Uplink Channel Descriptor) [6, 7, $9,14,15]$.

The preamble is used for frame synchronization at the receiver and it takes the first symbol duration in the DL subframe. The DL-MAP, UL-MAP, DCD, and UCD control messages contain information to inform the users in which burst they could find their individual data, also that parts in the data burst allocated to a certain user. In addition to contain the frame length, the frame number, the definition of the different burst profiles used in the frame, and the length and position of the ranging and resource request windows [8, 9]. The FCH, DLMAP, UL-MAP, DCD, and UCD messages are transmitted using QPSK1/2 MCS and the mandatory PUSC mode.

It is worth mentioning that most of the control messages (DL-MAP, UL-MAP, DCD, UCD) are listed in the standard documents [6, 7] by algorithms contain the overhead information. These algorithms, have been solved in order to extract the required overhead bytes. All the FCH, DL-MAP, UL-MAP, DCD, and UCD overhead calculations are adopted according to the standard documents and [9].

\subsection{FCH Message Overhead Calculation:}

FCH appears in every frame and it takes the first four transmitted subchannels in the first two data symbols following the preamble symbol of the DL subframe. The FCH contains the Downlink Frame Prefix (DLFP), which specifies the length of the DL-MAP message that immediately follows the FCH and the repetition coding used for the DL-MAP message [4]. The FCH is transmitted with four repetitions. The size of FCH is 24 bits. As the minimum 
size for the FEC block is 48 , the FCH data is doubled to have 48 bits. Subsequently, they are repeated 4 times and result in 192 bits or 24 bytes [9]. FCH message is classified as static overhead and it is fixed for all permutation modes.

\subsection{DL-MAP Message Overhead Calculation:}

The DL-MAP message is mapped to the slots starting after the FCH field and continues to the next PUSC symbols if necessary. The length of DL-MAP message varies depending on the physical information length, and the DL-MAP_IE [10]. However, DL-MAP overhead can be calculated as shown in equation (1):

$\mathrm{OH}_{\text {DL-MAP }}=\mathrm{OH}_{\text {DL-Static }}+\mathrm{OH}_{\text {DL-Dynamic }}+\mathrm{ZSE} *$ DL_ZS_IE

where, $\mathrm{OH}_{\text {DL-Static }}$ : static part overhead in DL MAP message, $\mathrm{OH}_{\text {DL-Dynamic: dynamic part }}$ overhead in DL MAP message, ZSE: zone switch enable, DL_ZS_IE: DL zone switch information elements.

ZSE $=0 \quad$ When the DL subframe contains a single zone with PUSC mode.

$\mathrm{ZSE}=1$ When the DL subframe contains more than one zone (PUSC+one/both other zones FUSC, AMC ).

The values of $\mathrm{OH}_{\mathrm{DL}-\mathrm{Stati}}, \mathrm{DL} \_\mathrm{ZS} \_\mathrm{IE}$ and $\mathrm{OH}_{\mathrm{DL}-\mathrm{Dynamic}}$ are calculated as follows:

$\mathrm{OH}_{\text {DL-Static }}=104$ bit $=13$ byte, DL_ZS_IE $=40$ bit $=5$ byte

$\mathrm{OH}_{\text {DL-Dynamic }}=$ DL-MAP_IE $* \mathrm{~N}_{\text {DL-users }}$

where, DL-MAP_IE: DL-MAP information elements, $\mathrm{N}_{\text {DL-users: }}$ number of users served by BS in the DL subframe.

When the DL zone of data bursts stay in PUSC permutation mode, or switched to FUSC permutation mode, the DL-MAP_IE is calculated as follows:

DL-MAP_IE $=60$ bit $=7.5$ byte

The resulting DL-MAP message overhead (in byte) when the DL zone of data bursts is switched to FUSC permutation mode is calculated as follows:

$\mathrm{OH}_{\text {DL-MAP }}($ byte $)=\operatorname{ceil}\left(13+5+7.5 * \mathrm{~N}_{\text {DL-users }}\right)=\operatorname{ceil}\left(18+7.5 * \mathrm{~N}_{\text {DL-users }}\right)$

And the resulting DL-MAP message overhead (in byte) when the DL zone of data bursts stays in PUSC permutation mode is calculated as follows:

$\mathrm{OH}_{\text {DL-MAP }}($ byte $)=\operatorname{ceil}\left(13+7.5 * \mathrm{~N}_{\text {DL-users }}\right)$

where, ceil: Represents the ceil function.

\subsection{UL-MAP Message Overhead Calculation:}

The UL-MAP message is mapped on the burst described by the first DL_MAP_IE of the DL-MAP message. The length of UL-MAP message varies depending on the physical information length, and the UL-MAP_IE. As in the case of the DL-MAP, the UL MAP overhead calculated according to equation (5).

$\mathrm{OH}_{\mathrm{UL}-\mathrm{MAP}}=\mathrm{OH}_{\mathrm{UL}-\mathrm{Static}}+\mathrm{OH}_{\mathrm{UL}-\mathrm{Dynamic}}+\mathrm{UL} \_$zone_IE

where, $\mathrm{OH}_{\mathrm{UL}-\mathrm{Static}}$ : static part overhead in UL MAP message, $\mathrm{OH}_{\mathrm{UL}-\mathrm{Dynamic}}$ : dynamic part overhead in UL MAP message, UL_zone_IE: UL zone information elements.

The values of $\mathrm{OH}_{\mathrm{UL}-\mathrm{Static}}$, UL_zone_IE and $\mathrm{OH}_{\mathrm{UL}-\mathrm{Dynamic}}$ are calculated as follows:

$\mathrm{OH}_{\mathrm{UL}-\mathrm{Static}}=64$ bit $=8$ byte, UL_zone_IE $=32$ bit $=4$ byte .

$\mathrm{OH}_{\mathrm{UL}-\mathrm{Dynamic}}=\mathrm{UL}-\mathrm{MAP} \_\mathrm{IE} * \mathrm{~N}_{\mathrm{UL} \text {-users }}$ 
where, UL-MAP_IE: UL-MAP information elements, $\mathrm{N}_{\text {UL-users: }}$ number of users accessing the UL subframe.

When the UL zone of data burst stay in PUSC permutation mode (FUSC is not considered as mandatory permutation mode in the UL subframe according to $[3,6,7])$, the UL-MAP_IE is calculated as follows:

UL-MAP_IE $=52$ bit $=6.5$ byte.

The resulting UL-MAP message overhead (in byte) when the DL zone of data bursts stays in PUSC permutation mode, or switches to FUSC permutation mode is calculated as follows:

$\mathrm{OH}_{\text {UL-MAP }}($ byte $)=\operatorname{ceil}\left(8+4+6.5 * \mathrm{~N}_{\text {UL-users }}\right)=\operatorname{ceil}\left(12+6.5 * \mathrm{~N}_{\text {UL-users }}\right)$

\subsection{DCD Message Overhead Calculation:}

The DCD message is a MAC management message, which is transmitted by the BS at a periodic interval (whose maximum value is 10 seconds) to define the characteristics of a downlink physical channel $[4,9]$.

The DCD message overheads is calculated as follows:

$\mathrm{OH}_{\mathrm{DCD}}=\mathrm{OH}_{\mathrm{DCD}-\text { Static }}+\mathrm{OH}_{\mathrm{DCD}-\text { Dynamic }}$

where, $\mathrm{OH}_{\mathrm{DCD}-\mathrm{Static}}$ : static part overhead in $\mathrm{DCD}$ message, $\mathrm{OH}_{\mathrm{DCD}-\mathrm{Dynamic}}$ : dynamic part overhead in DCD message.

$\mathrm{OH}_{\text {DCD-Static }}=24$ bit $=3$ byte.

$\mathrm{OH}_{\mathrm{DCD}-\mathrm{Dynamic}}=\mathrm{TLV}+\mathrm{DL} \_\mathrm{BP} * \mathrm{~N}_{\mathrm{DL} \text {-burst }}$

where, TLV: type-length-value of the encoded information for the overall downlink channel, DL_BP: DL burst profile format length, $\mathrm{N}_{\text {DL-burst }}$ Number of DL bursts in the DL subframe.

The TLV and DL_BP are calculated as follows:

$\mathrm{TLV}=103$ byte + ceil $\left(\left(3.5\right.\right.$ byte $\left.* \mathrm{~N}_{\text {DL-burst }}\right)+1$ byte $)$

DL_BP $=6$ byte.

As a result, the DCD message overhead (in byte) when the DL zone of data bursts stays in PUSC permutation mode, or switches to FUSC permutation mode is given in equation (11):

$\mathrm{OH}_{\mathrm{DCD}}($ byte $)=106+\operatorname{ceil}\left(\left(3.5 * \mathrm{~N}_{\text {DL-burst }}\right)+1\right)+\left(6 * \mathrm{~N}_{\text {DL-burst }}\right)$

\subsection{UCD Message Overhead Calculation:}

Like the DCD message, UCD message is a MAC management message, which is transmitted by the BS at a periodic interval (whose maximum value is 10 seconds) to define the characteristics of an uplink physical channel [9].

The UCD message overhead is given in equation (12).

$\mathrm{OH}_{\mathrm{UCD}}=\mathrm{OH}_{\mathrm{UCD}-\text { Static }}+\mathrm{OH}_{\mathrm{UCD}-\text { Dynamic }}$

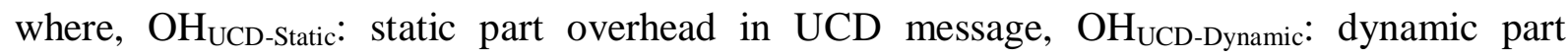
overhead in UCD message.

$\mathrm{OH}_{\mathrm{UCD}-\mathrm{Static}}=48$ bit $=6$ byte.

$\mathrm{OH}_{\mathrm{UCD} \text {-Dynamic }}=\mathrm{TLV}+\mathrm{UL} \_\mathrm{BP} * \mathrm{~N}_{\mathrm{UL} \text {-burst }}$

where, TLV: type-length-value of the encoded information for the overall uplink channel, UL_BP: UL burst profile format length, $\mathrm{N}_{\mathrm{UL}-\text { burst: }}$ number of UL bursts in the UL subframe.

The TLV and UL_BP are calculated as follows:

$\mathrm{TLV}=172$ byte, UL_BP $=9$ byte. 
As a results, the UCD message overhead (in byte) when the DL zone of data bursts stays in PUSC permutation mode, or switches to FUSC permutation mode is given in equation (14):

$\mathrm{OH}_{\mathrm{UCD}}($ byte $)=178+\left(9 * \mathrm{~N}_{\mathrm{UL}-\text { burst }}\right)$

\section{Capacity: Mathematical Analysis for the DL Subframe in FUSC and PUSC Permutation Modes:}

The present mathematical analysis focuses on the capacity calculations at the DL subframe for FUSC and PUSC permutation modes to obtain the maximum number of users that can be served by the BS in the DL direction. Since in this direction more resources allocated by the BS than in the UL direction, and this lead to give a good indication for the maximum capacity provided by the mobile WiMAX system. The MAC layer allocates the time-frequency resources to various users in units of slots. So, in order to calculate the DL throughput at the MAC layer, the overhead slots must be calculated and removed from the total DL subframe slots.

For the following mathematical analysis it is assumed a DL-OFDMA mobile WiMAX system with $10 \mathrm{MHz}$ bandwidth, FFT size of 1024 in TDD mode with $2 \mathrm{msec}$. frame duration, and a DL:UL ratio of 2:1.

Also, the mobile WiMAX system is assumed to be in steady state and having a specific number of users served by BS in the DL subframe, which are equal to the number of users in the UL subframe, $\mathrm{N}_{\mathrm{DL} \text {-users }}=\mathrm{N}_{\mathrm{UL} \text {-users }}=\mathrm{N}_{\text {users }}$.

\subsection{Physical Layer Throughput Calculations:}

In physical layer throughput calculations it is impossible to separate the DL and UL subframe symbols. Such that, the calculated data rate represents the whole TDD frame. The physical layer peak data rate calculated according to equation $(15)[16,17,18]$ as follows:

$\mathrm{R}_{\text {Physical }}=\mathrm{N}_{\text {data }} * \mathrm{~N}_{\mathrm{b}} * \mathrm{C}_{\mathrm{r}} / \mathrm{T}_{\mathrm{s}}$

where, $\mathrm{N}_{\text {data }}$ : number of data subcarriers, see table (1), $\mathrm{N}_{\mathrm{b}}$ : number of bits per modulation symbol, depends on the selected modulation scheme, $\mathrm{C}_{\mathrm{r}}$ : the coding rate, $\mathrm{T}_{\mathrm{s}}$ : OFDMA symbol duration, calculated as follows $[6,7]$ :

$$
\begin{aligned}
\mathrm{T}_{\mathrm{s}} & =\mathrm{T}_{\mathrm{b}}+\mathrm{T}_{\mathrm{g}}=\mathrm{T}_{\mathrm{b}}+\mathrm{T}_{\mathrm{b}} * \mathrm{CP}=\mathrm{T}_{\mathrm{b}} *(1+\mathrm{CP})=(1 / \Delta \mathrm{f}) *(1+\mathrm{CP})=\left(\mathrm{N}_{\mathrm{FFT}} / \mathrm{Fs}\right) *(1+\mathrm{CP}) \\
& =\mathrm{N}_{\mathrm{FFT}} /(\text { floor }(\mathrm{n} * \mathrm{BW} / 8000) * 8000) *(1+\mathrm{CP})
\end{aligned}
$$

where, $\mathrm{T}_{\mathrm{b}}$ : useful symbol time, $\mathrm{T}_{\mathrm{g}}$ : cyclic prefix duration, $\Delta \mathrm{f}$ : subcarrier frequency spacing, CP: Cyclic Prefix ratio, Fs: sampling frequency, n: sampling factor, $\mathrm{N}_{\mathrm{FFT}}$ : FFT size, BW: channel bandwidth, and floor: represents the floor function.

Now, according to the assumed DL OFDMA parameters and putting $\mathrm{CP}=1 / 8, \mathrm{n}=28 / 25, \mathrm{~T}_{\mathrm{s}}$ could be calculated using equation (16) as: $\mathrm{T}_{\mathrm{s}}=102.857 \mu \mathrm{sec}$.

\subsection{MAC Layer Throughput Calculations:}

As shown in sec. 4, the OFDMA frame structure is build according to the MAC layer assignments. In order to separate the DL and UL subframes throughputs, the physical layer throughput must be rewritten in terms of the number of symbols in the DL and UL subframes, respectively. The total number of symbols in the TDD frame are calculated as follows [16]: $\mathrm{N}_{\text {symbol }}^{\text {Total }}=$ floor $\left(\mathrm{T}_{\mathrm{f}} / \mathrm{T}_{\mathrm{s}}\right)$

where, $T_{\mathrm{f}}$ f frame duration. 
The peak TDD frame throughput at the MAC layer can be express in terms of $\mathrm{N}_{\text {symbol }}^{\text {Total }}$ as: $\mathrm{R}_{\mathrm{MAC}}^{\text {Total }}=\mathrm{N}_{\text {data }} * \mathrm{~N}_{\mathrm{b}} * \mathrm{C}_{\mathrm{r}} * \mathrm{~N}_{\text {symbol }}^{\text {Total }} / \mathrm{T}_{\mathrm{f}}$

Now, the peak DL subframe throughput at the MAC layer could be expressed as: $\mathrm{R}_{\mathrm{MAC}}^{\mathrm{DL}}=\mathrm{N}_{\text {data }} * \mathrm{~N}_{\mathrm{b}} * \mathrm{C}_{\mathrm{r}} * \mathrm{~N}_{\text {symbol }}^{\mathrm{DL}} / \mathrm{T}_{\mathrm{f}}$

where, $\mathrm{N}_{\text {symbol }}^{\mathrm{DL}}$ : number of OFDMA symbols in the DL subframe.

Also, the peak UL subframe throughput at the MAC layer is expressed as follows: $\mathrm{R}_{\mathrm{MAC}}^{\mathrm{UL}}=\mathrm{N}_{\text {data }} * \mathrm{~N}_{\mathrm{b}} * \mathrm{C}_{\mathrm{r}} * \mathrm{~N}_{\mathrm{symbol}}^{\mathrm{UL}} / \mathrm{T}_{\mathrm{f}}$

where, $\mathrm{N}_{\text {symbol }}^{\mathrm{UL}}$ : number of OFDMA symbols in the UL subframe.

Note that the $\mathrm{N}_{\text {symbol }}^{\mathrm{DL}}, \mathrm{N}_{\text {symbol }}^{\mathrm{UL}}$ depend on DL:UL ratio after subtracting the TTG and RTG durations.

Now, by substituting $\mathrm{T}_{\mathrm{f}}=2$ msec., $\mathrm{T}_{\mathrm{s}}=102.857 \mu \mathrm{sec}$. in equation (17), and assuming that the TTG \& RTG takes about 0.44 symbol duration (i.e. TTG+RTG $=45.7 \mu \mathrm{sec}$.) [19]. We can obtain the followings:

$\mathrm{N}_{\text {symbol }}^{\text {Total }}=$ floor $\left(\mathrm{T}_{\mathrm{f}} / \mathrm{T}_{\mathrm{s}}\right)=$ floor $\left(2 * 10^{-3} / 102.857 * 10^{-6}\right)=$ floor $(19.44)=19$ symbols

The preamble takes only one symbol, and the DL:UL ratio=2:1 that leads to: $\mathrm{N}_{\text {symbol }}^{\text {Total }}=18$ symbols, $\mathrm{N}_{\text {symbol }}^{\mathrm{DL}}=12$ symbols, $\mathrm{N}_{\text {symbol }}^{\mathrm{UL}}=6$ symbols.

The total MAC messages overheads in bytes are calculated according to equation (21): $\mathrm{OH}_{\mathrm{MAC}}($ byte $)=\mathrm{FCH}($ byte $)+\mathrm{OH}_{\text {DL-MAP }}($ byte $)+\mathrm{OH}_{\mathrm{DCD}}($ byte $)+\mathrm{OH}_{\mathrm{UL}-\mathrm{MAP}}($ byte $)$ $+\mathrm{OH}_{\mathrm{UCD}}($ byte)

By assuming that DCD, UCD repeated periodically every $100 \mathrm{msec}$. The total MAC messages overheads in bytes for FUSC permutation mode become: $\mathrm{OH}_{\mathrm{MAC}}^{\text {FUSC }}($ byte $)=24+$ ceil $\left(18+7.5 * \mathrm{~N}_{\text {DL-users }}\right)+\left[106+\right.$ ceil $\left.\left(\left(3.5 * \mathrm{~N}_{\text {DL-burst }}\right)+1\right)+\left(6 * \mathrm{~N}_{\text {DL-burst }}\right)\right] * \mathrm{~T}_{\mathrm{f}} / 100+$ $\operatorname{ceil}\left(12+6.5 * \mathrm{~N}_{\mathrm{UL}-\text { users }}\right)+\left[178+\left(9 * \mathrm{~N}_{\mathrm{UL}-\text { burst }}\right)\right] * \mathrm{~T}_{\mathrm{f}} / 100$

Also, the total MAC messages overheads (in bytes) for PUSC permutation mode become: $\mathrm{OH}_{\mathrm{MAC}}^{\text {PUSC }}($ byte $)=24+$ ceil $\left(13+7.5 * \mathrm{~N}_{\text {DL-users }}\right)+\left[106+\right.$ ceil $\left.\left(\left(3.5 * \mathrm{~N}_{\text {DL-burst }}\right)+1\right)+\left(6 * \mathrm{~N}_{\text {DL-burst }}\right)\right] * \mathrm{~T}_{\mathrm{f}} / 100+$ ceil $\left(12+6.5 * \mathrm{~N}_{\text {UL-users }}\right)+\left[178+\left(9 * \mathrm{~N}_{\text {UL-burst }}\right)\right] * \mathrm{~T}_{\mathrm{f}} / 100$

Now, to express the calculated $\mathrm{OH}_{\mathrm{MAC}}^{\mathrm{FuSC}}$ (byte) and $\mathrm{OH}_{\mathrm{MAC}}^{\mathrm{PUSC}}$ (byte) in terms of the minimum MAC allocation unit (slot), we need to calculate the slot size in terms of bytes (Slz (byte)). This requires to calculate the time-frequency slot parameters. The first, is the number of subcarriers per subchannel per slot $\left(\mathrm{N}_{\text {cr-ch-slot }}=\mathrm{N}_{\text {data }} / \mathrm{N}_{\mathrm{ch}}\right)$ in which, the slot consists from one subchannel for all subcarrier permutation modes in frequency domain, and the values of $\mathrm{N}_{\text {data, }}$, $\mathrm{N}_{\mathrm{ch}}$ are given in table (1). The second, is the number of OFDMA symbols per slot $\left(\mathrm{N}_{\text {sym-slot }}\right)$ in which, the slot consists from one OFDMA symbol in the FUSC mode, and two OFDMA symbols in the PUSC mode in time domain. As a result, it is now possible to calculate slot size in byte units for any burst profile and any subcarrier permutation mode as shown in equation (24).

Slz (byte) $=\mathrm{N}_{\text {cr-ch-slot }} * \mathrm{~N}_{\text {sym-slot }} * \mathrm{~N}_{\mathrm{b}} * \mathrm{C}_{\mathrm{r}} / 8$ 
The $\mathrm{R}_{\text {Physical }}, \mathrm{R}_{\text {MAC }}^{\mathrm{DL}}$ and the Slz (byte) are calculated for the recommended MCSs in the mobile WiMAX system [3, 13], and the results are listed in table (2).

Table (2): Physical layer and DL MAC layer throughput and slot size of the PUSC and FUSC permutation modes for the recommended MCSs in mobile WiMAX system

\begin{tabular}{|c|c|c|c|c|c|c|c|}
\hline \multirow[b]{2}{*}{ MCSs } & \multirow[b]{2}{*}{$\mathrm{N}_{\mathrm{b}}$ (bits) } & \multirow{2}{*}{$\begin{array}{l}\text { CTC } \\
\text { Rate } \\
\left(C_{\mathrm{r}}\right)\end{array}$} & \multicolumn{2}{|c|}{ FUSC } & \multicolumn{2}{|c|}{ PUSC } & \multirow[b]{2}{*}{ Slz (byte) } \\
\hline & & & $\begin{array}{l}\mathrm{R}_{\text {Physical }} \\
\text { (Mbps) }\end{array}$ & $\begin{array}{c}\mathrm{R}_{\mathrm{MAC}}^{\mathrm{DL}} \\
(\mathrm{Mbps})\end{array}$ & $\begin{array}{l}\mathrm{R}_{\text {Physical }} \\
\text { (Mbps) }\end{array}$ & $\begin{array}{c}\mathrm{R}_{\mathrm{MAC}}^{\mathrm{DL}} \\
(\mathrm{Mbps})\end{array}$ & \\
\hline QPSK & 2 & $1 / 2$ & 7.467 & 4.608 & 7.001 & 4.32 & 6 \\
\hline QPSK & 2 & $3 / 4$ & 11.201 & 6.912 & 10.501 & 6.48 & 9 \\
\hline 16QAM & 4 & $1 / 2$ & 14.935 & 9.216 & 14.002 & 8.64 & 12 \\
\hline 16QAM & 4 & $3 / 4$ & 22.403 & 13.824 & 21.003 & 12.96 & 18 \\
\hline 64QAM & 6 & $1 / 2$ & 22.403 & 13.824 & 21.003 & 12.96 & 18 \\
\hline 64QAM & 6 & $3 / 4$ & 33.605 & 20.736 & 31.505 & 19.44 & 27 \\
\hline 64QAM & 6 & $5 / 6$ & 37.339 & 23.040 & 35.005 & 21.6 & 30 \\
\hline
\end{tabular}

Since the MAC overhead messages are always sent using the most robust MCS, QPSK1/2, where Slz (byte) $=6$ bytes/slot. Then, the number of MAC overhead slots for FUSC and for PUSC modes due to MAC control messages in DL subframe can be calculated as follows:

$\mathrm{N}_{\mathrm{OH}-\mathrm{MAC}}^{\mathrm{FUSC}}($ slot $)=\mathrm{OH}_{\mathrm{MAC}}^{\mathrm{FUSC}}($ byte $) / 6 \quad$ for FUSC mode

$\mathrm{N}_{\mathrm{OH}-\mathrm{MAC}}^{\mathrm{PUSC}}(\mathrm{slot})=\mathrm{OH}_{\mathrm{MAC}}^{\mathrm{PUSC}}($ byte $) / 6 \quad$ for PUSC mode

Now, the number of allocated data slots by the MAC layer in the DL subframe for the FUSC and PUSC modes, which considered as the available physical resources by the MAC layer, can be calculated as follows:

$\mathrm{N}_{\text {data-MAC }}^{\text {FuSC }}($ slot $)=\mathrm{N}_{\text {totat-MAC }}^{\text {FuSC }}($ slot $)-\mathrm{N}_{\text {OH-MAC }}^{\text {FusC }}($ slot $)$

$\mathrm{N}_{\text {data-MAC }}^{\text {PUSC }}($ slot $)=\mathrm{N}_{\text {totat-MAC }}^{\text {PUSC }}($ slot $)-\mathrm{N}_{\text {OH-MAC }}^{\text {PUSC }}($ slot $)$

where, $\mathrm{N}_{\text {total-MAC }}^{\text {FUSC }}\left(\right.$ slot), $\mathrm{N}_{\text {tota-MAC }}^{\text {PUSC }}($ slot): the total number of slots in the DL subframe for the FUSC and PUSC modes respectively, which considered as the total physical resources by the MAC layer, and calculated as follows:

$\mathrm{N}_{\text {tota-MAC }}^{\text {FUS }}($ slot $)=\mathrm{N}_{\text {ch }} * \mathrm{~N}_{\text {symbol }}^{\mathrm{DL}}=16 * 12=192$
$\mathrm{~N}_{\text {tota-MAC }}^{\text {PUSC }}($ slot $)=\mathrm{N}_{\mathrm{ch}} * \mathrm{~N}_{\text {symbol }}^{\mathrm{DL}} / 2=30 * 6=180$

Then the MAC throughput at the DL subframe for the FUSC and PUSC permutation modes for multiple MCSs (burst profiles) is calculated as follows [4]:

$\mathrm{R}_{\mathrm{DL}-\mathrm{MAC}}^{\text {FUSC }}(\mathrm{bps})=8000 * \mathrm{~N}_{\text {data-MAC }}^{\text {FuSC }}(\mathrm{slot}) * \sum_{\mathrm{i}=1}^{\mathrm{N}_{\mathrm{DL}-\text { burst }}}\left(\mathrm{Slz}_{\mathrm{i}} * \mathrm{~W}_{\mathrm{i}}\right) / \mathrm{T}_{\mathrm{f}}$

$\mathrm{R}_{\mathrm{DL}-\mathrm{MAC}}^{\text {PUSC }}(\mathrm{bps})=8000 * \mathrm{~N}_{\text {data-MAC }}^{\text {PUSC }}(\mathrm{slot}) * \sum_{\mathrm{i}=1}^{\mathrm{N}_{\mathrm{DL}-\text { burst }}}\left(\mathrm{Slz}_{\mathrm{i}} * \mathrm{~W}_{\mathrm{i}}\right) / \mathrm{T}_{\mathrm{f}}$

where, $\mathrm{Slz}_{\mathrm{i}}$ : slot size (in byte) for the ith MCS (burst profile), $\mathrm{W}_{\mathrm{i}}$ : weighting percentage of the coverage area that served by the ith MCS. 


\section{Simulation Parameters and Results Analysis:}

The physical layer simulations is considered as a single user system trying to transmit in DL direction as quickly as possible through the channel with variable SNR as illustrated in figure (1). The physical layer performance is considered as an important indicator to show the behavior of the system working in a proposed multipath mixed user channel. Also, providing important information about the best burst profiles to carry information efficiently between the BS and MS. This is done under the consideration of the QoS requirements in terms of PER and SNR for video streaming applications.

The physical layer simulation associated with the DL direction having the following BSMS parameters $[6,7,12,13]$ : carrier frequency $\left(f_{c}\right)$ of $2.3 \mathrm{GHz}, B S$ antenna gain and transmitted power of $15 \mathrm{dBi}$ and $30 \mathrm{dBm}$, respectively. The antenna configuration is SISO system, MS antenna gain and noise figure of $0 \mathrm{dBi}$ and $7 \mathrm{~dB}$, respectively. Also, it is assumed that there is a perfect CSI. In addition to the assumed parameters mentioned in sec. 6 . Under the same above-mentioned parameters, a complete simulation model for the MAC and physical layers are built using OPNET 14.5 modular. The MSs distributed in the cell of $2.5 \mathrm{~km}$ diameter as depicted in figure (3) and figure (4) for the FUSC and PUSC modes, respectively. The MSs moving inside the cell according to a proposed trajectories related to the pedestrian and vehicular speeds weights that mentioned previously in the proposed mixed user channel section.

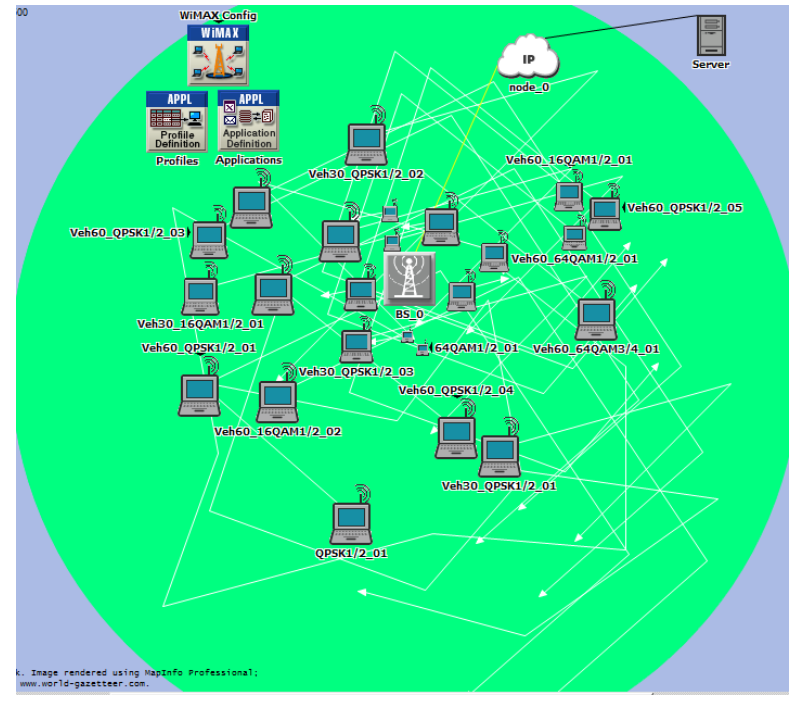

Figure (3): MSs distribution around the BS in the cell with the proposed mobility trajectories for FUSC mode

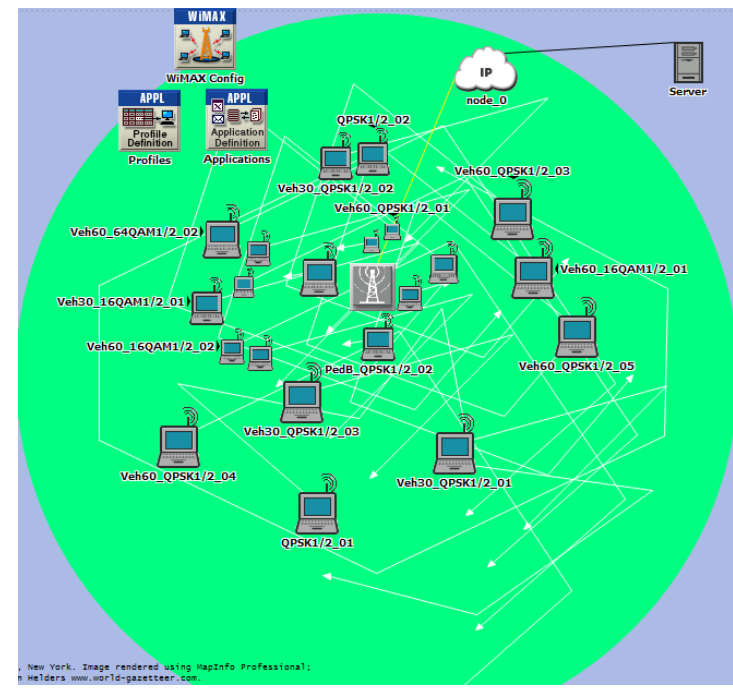

Figure (4): MSs distribution around the BS in the cell with the proposed mobility trajectories for PUSC mode

Figure (5) shows the attributes of randomly chosen MS from the maximum served MSs (a)for FUSC mode, (b)- for PUSC mode. Also, figure (6) shows the mobile WiMAX configuration attributes for the OPNET simulation model (a)- for FUSC mode, (b)- for PUSC mode. 


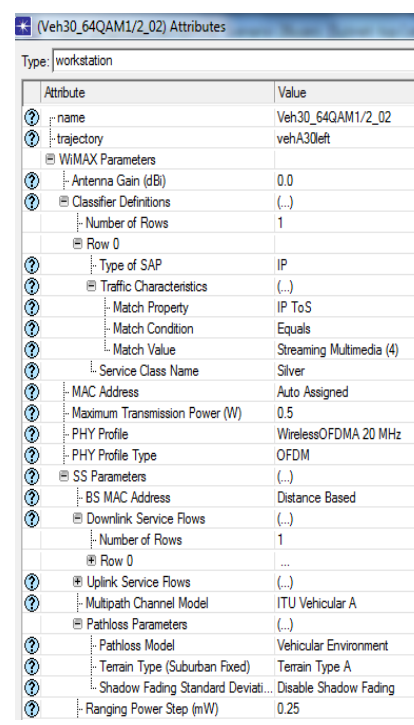

(a)

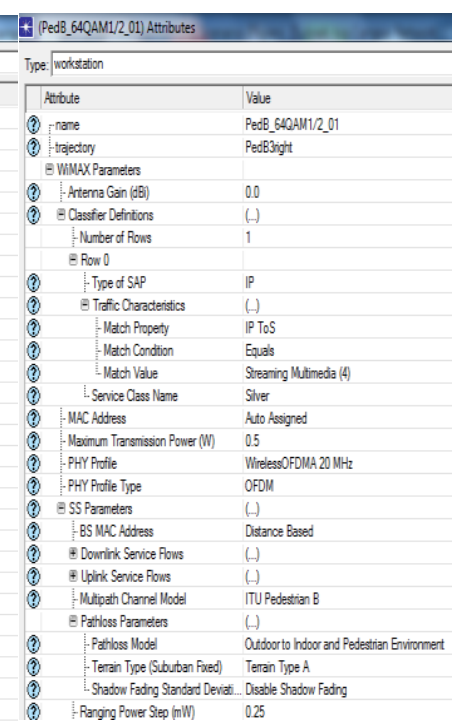

(b)

Figure (5): MS attributes for the OPNET simulation model (a)- FUSC mode (b)- PUSC mode

\subsection{System Performance in Terms of PER:}

Figures (7) and (8) show the simulation results of PER vs. SNR for the FUSC, PUSC permutation modes, respectively in the proposed multipath mixed user channel. It is obvious from the two figures that the most robust MCS (QPSK1/2) shows the best PER performance in terms of the SNR in comparison with the least robust MCS (64QAM5/6). But this is at the expense of the peak data rate, which is behaved conversely with the PER performance, see figures (9) and (10). Also it is obvious that the PER performance of 16QAM1/2 and 64QAM1/2 are so close to QPSK3/4 and 16QAM3/4, respectively; although the first two MCSs represent the higher modulation schemes, which carrying more bits per symbol. This is due to the use of puncturing process in the 3/4 coding rate, which lead to decrease the minimum distance of the turbo code.

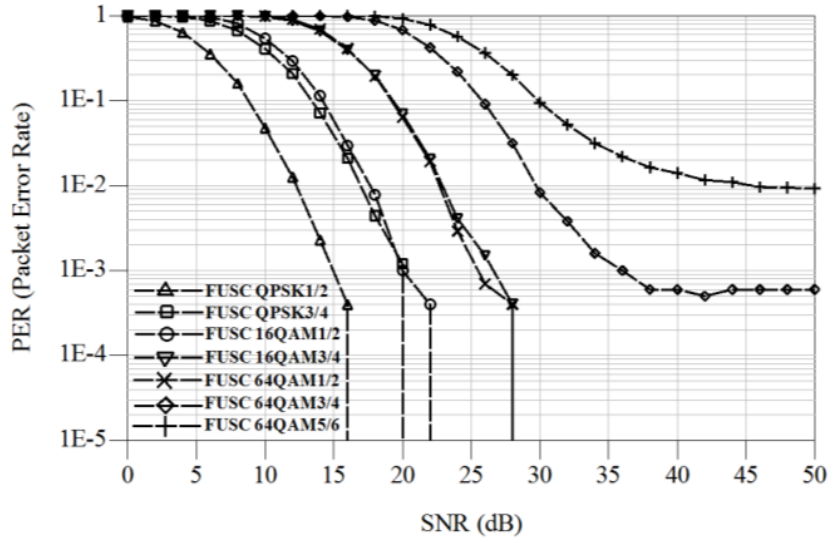

Figure (7): PER vs. SNR for FUSC permutation mode and various link speeds in the proposed mixed user channel

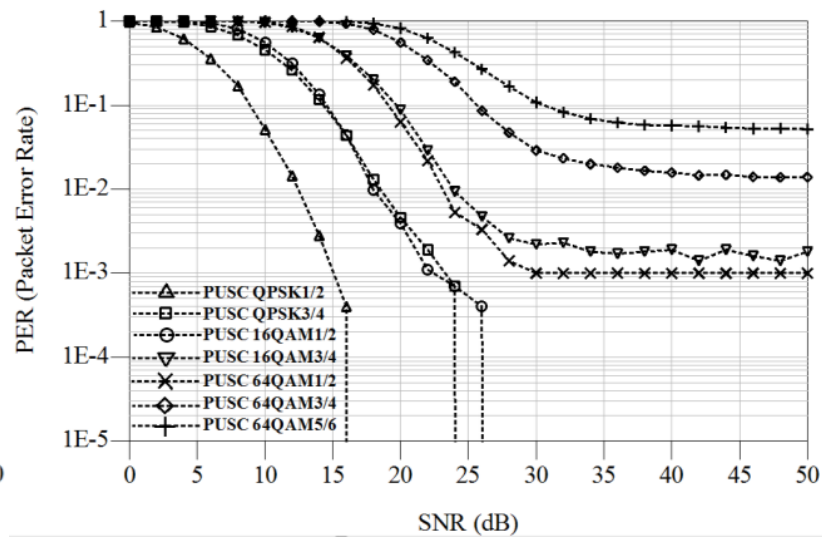

Figure (8): PER vs. SNR for PUSC permutation mode and various link speeds in the proposed mixed user channel 


\subsection{System Performance in Terms of Physical Layer Data Rate:}

The peak physical layer error-free DL throughput ( $\left.\mathrm{R}_{\text {Physical }}\right)$ per BS is given in equation (15) for a certain link speed (MCS). Now, in order to estimate the actual DL throughput $\left(\mathrm{R}_{\text {Actual }}\right)$ from the peak physical layer DL throughput, equation $(29)$ are used $[17,18,20]$ :

$\mathrm{R}_{\text {Actual }}=\mathrm{R}_{\text {Physical }}(1-\mathrm{PER})$

where PER depends on many factors like, SNR at the receiver, the selected MCS according to the adaptive modulation and coding technique, and the channel characteristics.

Figures (9) and (10) show the simulation results of $\mathrm{R}_{\text {Actual }}$ vs. SNR for various link speeds of the FUSC and PUSC permutation modes, respectively. This simulation results can be considered as a combination of the results in figures (7), (8) and equation (29), in which the PER are taken without any constraints imposed by the QoS for any application. It is clear that the more robust MCS reached its peak physical layer DL throughput at lower SNR in comparison with the less robust MCSs. As an example, the QPSK1/2 requires about 10dB SNR, while the 64QAM5/6 requires about $36 \mathrm{~dB}$ to reach their peak physical layer DL throughput.

The mobile WiMAX system is substantially used to provide users with applications affluent by multimedia services. The QoS is of particular concern for the high data rate video and multimedia applications. The required QoS is usually specified by four parameters: required bandwidth, maximum end-to-end delay, maximum jitter and maximum BER (Bit Error Rate) or PER (Packet Error Rate) [21]. In this throughput simulation the application is assumed to be video streaming for both FUSC, PUSC permutation modes. The QoS requirements for this video streaming in terms of DL throughput and PER is as follows:

DL Throughput $=\left(1-10^{4}\right) \mathrm{kbps}[21]$.

$\operatorname{PER}=\left(1 * 10^{-3}-3 * 10^{-3}\right)$ to be in good video quality [22].

In the present simulation, the PER threshold that considered the highest PER acceptable for video streaming application must be $\leq 3^{*} 10^{-3}$. Any PER in excess of this value is assumed to be too severe to maintain a practical data link.

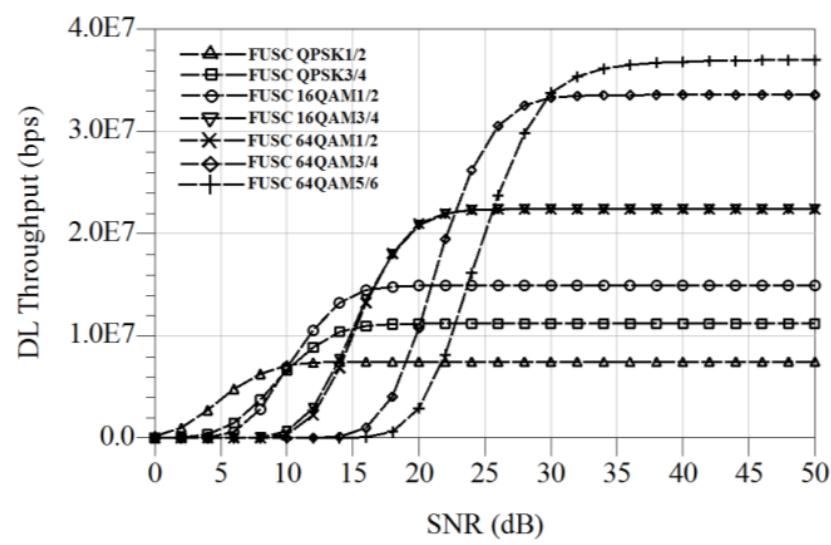

Figure (9): DL throughput vs. SNR for FUSC permutation mode and various link speeds

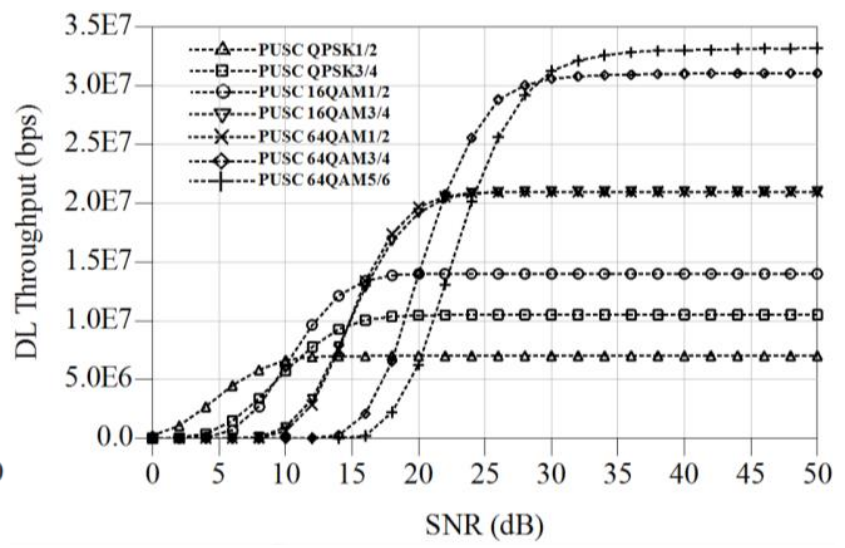

Figure (10): DL throughput vs. SNR for FUSC permutation mode and various link speeds

By applying the PER threshold $\left(3 * 10^{-3}\right)$ upon the simulation results in figure (7) and figure (8), the resulting burst profiles that meet the PER threshold constraints can be obtained as shown in figures (11) and (12) for FUSC, PUSC modes, respectively. These two figures show 
the comparison results for DL throughput vs. SNR and the suitable link speeds to acquire the PER threshold constraint.

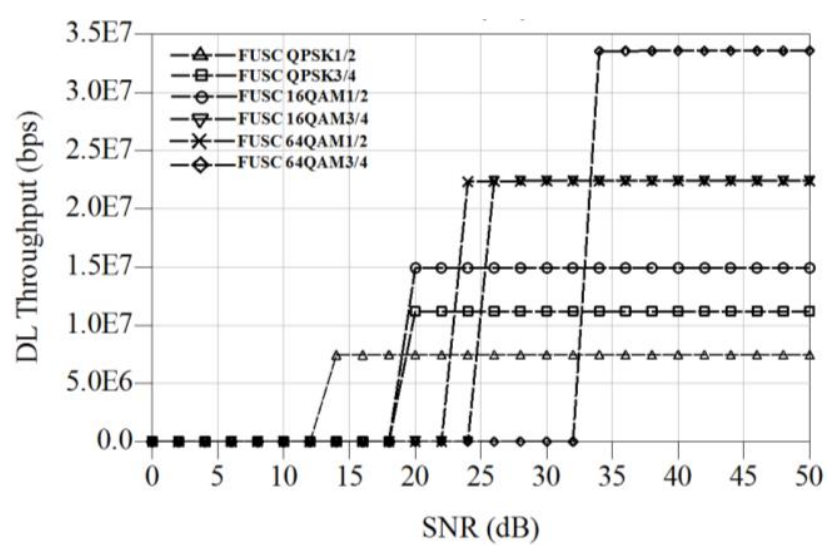

Figure (11): DL throughput vs. SNR for FUSC subcarrier permutation mode and various link speeds at $3 * 10^{-3}$ PER threshold

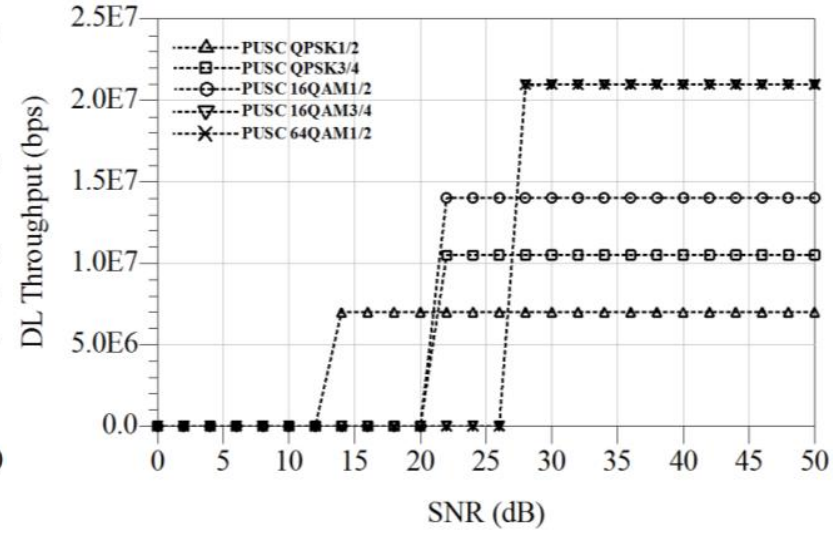

Figure (12): DL throughput vs. SNR for PUSC subcarrier permutation mode and various link speeds at $3 * 10^{-3}$ PER threshold

Also, figures (11) and (12) give good indication about that MSCs (burst profiles) which are satisfying the PER threshold value for the video streaming application in a mobile WiMAX system working in the proposed multipath mixed user channel.

It is also clear from figures (11) and (12) that the QPSK3/4 and the 16QAM1/2 starting at the same SNR, this is due to their very close PER performance, as shown in figures (7) and (8). As a result when the system decides to switch to one of these MCSs at that SNR, it will choses the MCS with the higher data rate one, which is the 16QAM1/2 and neglect the QPSK3/4 MCS. Moreover, in figure (12), the 16QAM3/4 and 64QAM1/2 starting to be in use at the same SNR and the provided data rate are the same. Thus, in this case when the system decides to switch to one of these MCSs at that SNR, it will chooses the MCS with the more powerful coding rate, which is the 64QAM1/2 and neglect the 16QAM3/4.

The resulting burst profiles (QPSK1/2, 16QAM1/2, 64QAM1/2, 64QAM3/4) shown in figure (11), and (QPSK1/2, 16QAM1/2, 64QAM1/2) shown in figure (12) for FUSC and PUSC modes. This is because they unveil the physical layer capabilities that meet the QoS requirements for the video streaming application.

\subsection{System Performance in Terms of MAC Layer Data Rate:}

This MAC layer data rate calculations are depend on the DL subframe structure in which each burst are allocated by a single MCS as illustrated in sec. 4. This leads to an important fact, which is the number of used MCSs in the DL subframe are equal to the number of DL bursts $\left(\mathrm{N}_{\mathrm{DL}-\text { burst }}\right)$ in the DL subframe. Now, returning to equations (27) and (28) to evaluate the MAC layer throughput, the $\mathrm{N}_{\text {data-MAC }}^{\text {FUSC }}$ (slot) and $\mathrm{N}_{\text {data-MAC }}^{\text {PUSC }}$ (slot) are calculated according to equations (25) and (26), respectively. The $\mathrm{Slz}_{\mathrm{i}}$ values are located in table (2) for all the MCSs. The $\mathrm{N}_{\text {DL-burst }}$ values are obtained from the physical layer simulation results, which represents the number of successfully working MCSs. These MCSs values are summaries in table (3) for the FUSC permutation mode, and table (4) for the PUSC permutation mode. The last factor in equations (27) and (28) is the weighting percentage $\left(\mathrm{W}_{\mathrm{i}}\right)$ of the coverage area that served by the ith MCS. This factor represents the ratio of the circular strip area of a certain MCS to the 
total coverage area of the served cell by the mobile WiMAX system. This circular strip area can be calculated depending on the BS maximum coverage distance of the ith MCS.

The BS maximum coverage distance $(\mathrm{D})$ is related to the channel path loss $\left(\mathrm{P}_{\mathrm{L}}(\mathrm{dB})\right)$ propagation model. In ITU-R M.1225 Recommendation [12], the suggested path loss propagation model for vehicular test environment is shown in equation (30), and for pedestrian test environment is shown in equation (31):

$\mathrm{P}_{\mathrm{L}}(\mathrm{dB})=40\left(1-4 * 10^{-3} * \Delta \mathrm{h}_{\mathrm{b}}\right) * \log _{10}(\mathrm{D})-18 \log _{10}\left(\Delta \mathrm{h}_{\mathrm{b}}\right)+21 \log _{10}\left(\mathrm{f}_{\mathrm{c}}\right)+80$

$\mathrm{P}_{\mathrm{L}}(\mathrm{dB})=40 \log _{10}(\mathrm{D})+30 \log _{10}\left(\mathrm{f}_{\mathrm{c}}\right)+49$

where $P_{L}(d B)$ : the average path loss between the BS and MS, D: represents BS-MS separation distance in $(\mathrm{km})$, $\mathrm{f}_{\mathrm{c}}$ : the carrier frequency in $(\mathrm{MHz})$ and $\Delta \mathrm{h}_{\mathrm{b}}$ : the $\mathrm{BS}$ height measured from the average rooftop level.

The path loss can also be calculated according to the link budget equation as follows [19]: $\mathrm{P}_{\mathrm{L}}(\mathrm{dB})=\mathrm{P}_{\mathrm{T}}(\mathrm{dBm})+\mathrm{G}_{\mathrm{BS}}(\mathrm{dB})+\mathrm{G}_{\mathrm{MS}}(\mathrm{dB})-\mathrm{SNR}(\mathrm{dB})-\mathrm{NF}(\mathrm{dB})-\mathrm{ThN}(\mathrm{dBm})$

where $\mathrm{P}_{\mathrm{T}}$ : the $\mathrm{BS}$ transmit power, $\mathrm{G}_{\mathrm{MS}}$ : the $\mathrm{MS}$ antenna gain, $\mathrm{G}_{\mathrm{BS}}$ : the $\mathrm{BS}$ antenna gain, SNR: the received signal to noise ratio, NF: the receiver noise figure, and $\mathrm{ThN}$ : the Thermal Noise $=-103.977 \mathrm{dBm}$.

By substituting equation (32) once into equation (30) and once into equation (31) and applying the assumed physical layer parameters mentioned in sec. 7 with $\Delta \mathrm{h}_{\mathrm{b}}=15 \mathrm{~m}$. We can get a direct relationship between the BS maximum coverage distance (D) and the received SNR for the vehicular environment as shown in equation (33), and for pedestrian environment as shown in equation (34):

$$
\begin{aligned}
& \mathrm{D}(\mathrm{km})=10^{0.33379-\frac{\mathrm{SNR}}{37.6}} \\
& \mathrm{D}(\mathrm{km})=10^{-0.196865-\frac{\mathrm{SNR}}{40}}
\end{aligned}
$$

Based on equations (33) and (34) with the simulation results for maximum and minimum SNR for the working MCSs in figures (11) and (12), and by considering the proposed mixed user channel weights $80 \%$ and $20 \%$ for the vehicular and pedestrian environments respectively, as mentioned earlier in sec. 3 . The weighting percentage $\left(\mathrm{W}_{\mathrm{i}}\right)$ of the coverage area for the ith successfully working MCS is calculated and listed with the maximum and minimum SNR in table (3) for the FUSC permutation mode, and in table (4) for the PUSC permutation mode.

Table (3): The $\mathrm{W}_{\mathrm{i}}$ weighting percentage of the coverage area for the ith MCS with its maximum and minimum SNR for the FUSC mode

\begin{tabular}{|c|c|c|c|}
\hline MCS & $\begin{array}{c}\text { Minimum } \\
\text { SNR }\end{array}$ & $\begin{array}{c}\text { Maximum } \\
\text { SNR }\end{array}$ & $\begin{array}{c}\text { Weighting } \\
\text { ratio Wi\% }\end{array}$ \\
\hline QPSK1/2 & 14 & 20 & 52 \\
\hline 16QAM1/2 & 20 & 24 & 18 \\
\hline 64QAM1/2 & 24 & 34 & 21 \\
\hline 64QAM3/4 & 34 & 50 & 9 \\
\hline
\end{tabular}

Table (4): The $\mathrm{W}_{\mathrm{i}}$ weighting percentage of the coverage area for the ith MCS with its maximum and minimum SNR for the PUSC mode

\begin{tabular}{|c|c|c|c|}
\hline MCS & $\begin{array}{c}\text { Minimum } \\
\text { SNR }\end{array}$ & $\begin{array}{c}\text { Maximum } \\
\text { SNR }\end{array}$ & $\begin{array}{c}\text { Weighting } \\
\text { ratio Wi\% }\end{array}$ \\
\hline QPSK1/2 & 14 & 22 & 62 \\
\hline 16QAM1/2 & 22 & 28 & 20 \\
\hline 64QAM1/2 & 28 & 50 & 18 \\
\hline
\end{tabular}

In this work the users are assumed to be distributed randomly in the coverage area of the cell that served by the BS. 
The requested application (service) by all users is assumed to be Mobile Phone Video (H.264 Advanced Simple Profile(ASP), 176 kbps, 176×144 pixels, 20 Frame/Second) [23].

The required number of data slots in the DL subframe to accommodate the requested application data rate $\left(\mathrm{R}_{\mathrm{app}}=176 \mathrm{kbps}\right)$ as a function of the number of users can be calculated for the two permutation modes FUSC, PUSC as follows:

$\mathrm{N}_{\text {DL-app }}($ slot $)=\mathrm{R}_{\text {app }} / 8 * \mathrm{~T}_{\mathrm{f}} * \mathrm{~N}_{\text {users }} * \sum_{\mathrm{i}=1}^{\mathrm{N}_{\mathrm{DL}-\text { burt }}}\left(\mathrm{W}_{\mathrm{i}} / \mathrm{Slz}_{\mathrm{i}}\right)$

The requested data rate by users in the DL subframe can be calculated in similar way to equations (27) and (28) as follows:

$\mathrm{R}_{\text {Requested }}(\mathrm{bps})=8000 * \mathrm{~N}_{\text {DL-app }}($ slot $) * \sum_{\mathrm{i}=1}^{\mathrm{N}_{\mathrm{DL}-\text { burst }}}\left(\mathrm{Slz}_{\mathrm{i}} \times \mathrm{W}_{\mathrm{i}}\right) / \mathrm{T}_{\mathrm{f}}$

The available data rate (resources) at the DL subframe is equal to the MAC data rate at the DL subframe, which are given in equations (27) and (28) for the two permutation modes FUSC and PUSC, respectively:

$\mathrm{R}_{\text {Available }}^{\text {FUSC }}(\mathrm{bps})=\mathrm{R}_{\mathrm{DL}-\mathrm{MAC}}^{\text {FUSC }}(\mathrm{bps})$
$\mathrm{R}_{\text {Available }}^{\text {PUSC }}(\mathrm{bps})=\mathrm{R}_{\mathrm{DL}-\mathrm{MAC}}^{\text {PUSC }}(\mathrm{bps})$

The maximum number of users (system capacity) that can be served simultaneously by the BS in the DL subframe are obtained analytically by increasing the number of users in step by step progressively and computing the values of $\mathrm{R}_{\text {Available }}(\mathrm{bps})$, which will decrease in turn, and computing the values of $R_{\text {Requested }}(b p s)$, which will increase in turn, and calculating the values of $R_{\text {Available }}(b p s) / R_{\text {Requested }}(b p s)$ at each step. When the quotient of $R_{\text {Available }}(b p s) / R_{\text {Requested }}(b p s)$ $=1$, the maximum number of users that can be served are attainable.

The OPNET simulation model to evaluate the maximum number of users (system capacity) that can be served simultaneously by the BS in the DL subframe for both FUSC and PUSC modes, are built according to different scenarios, each consists of a number of users distributed in the serving cell according to two weighting parameters: the first is the burst profile weighting ratio, in which the MCSs are distributed to users according to their locations in different ranges around the BS, these weighting ratios are calculated as given in tables (3) and (4). The second parameter is related to the mobility speed for each user in the scenario, which is calculated according to the proposed mixed user channel speed weighting ratios given in sec. 3 . Then by combining the two weighting ratios, we can get the users distribution around the BS in each scenario with different burst profiles and different users speed, as illustrated in figures (3) and (4).

The OPNET simulation results and the MAC layer analytical results that are based on the physical layer simulation results, to calculate the maximum number of users requesting a video phone service from the serving BS are shown in figure (13) for FUSC permutation mode, and figure (14) for PUSC permutation mode.

It is obvious from figure (13) that the maximum number of users calculated according to the analytical and simulation results are limited to 24 users for the FUSC mode. While figure (14) shows that the maximum number of users are limited to 21 users in the PUSC mode. Also, the two figures point out the convergence in the analytical and OPNET simulation results when reaching the maximum number of users for both permutation modes. However, when increasing the number of users more than the above limits, the quotient of $\mathrm{R}_{\text {Available }}(\mathrm{bps}) / \mathrm{R}_{\text {Requested }}(\mathrm{bps})$ become less than one, which means that there are no enough 
resources (slots) at the DL subframe to be assigned to more users with that requested application.

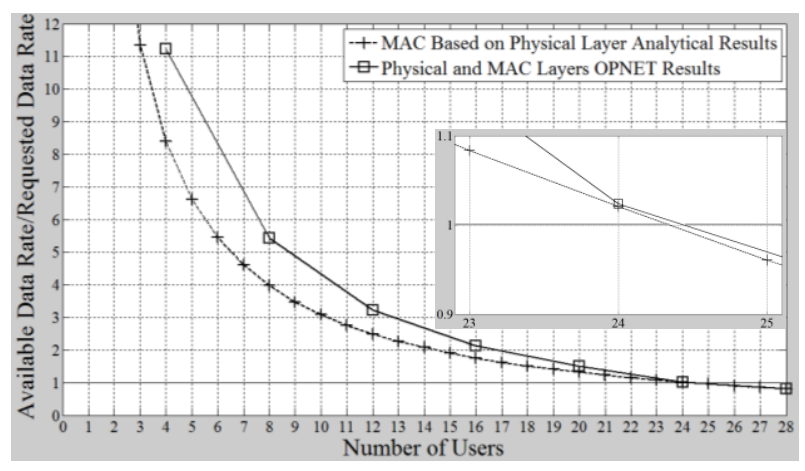

Figure (13): Maximum number of users in the DL subframe for the FUSC permutation mode

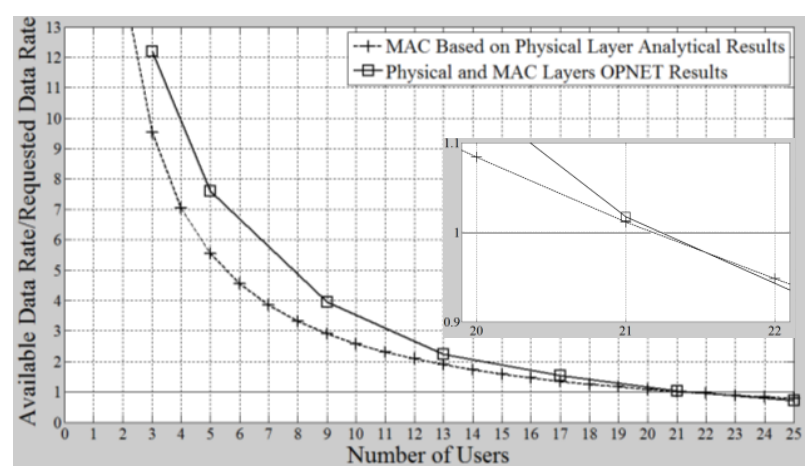

Figure (14): Maximum number of users in the DL subframe for the PUSC permutation mode

\section{Conclusion:}

The physical layer simulation results in the proposed ITU-R mixed user channel show that only four burst profiles (QPSK1/2, 16QAM1/2, 64QAM1/2, 64QAM3/4) in the FUSC mode and only three burst profiles (QPSK1/2, 16QAM1/2, 64QAM1/2) in PUSC mode meet the QoS requirements for the video streaming application. It is also important to see that not all the burst profiles that meet the QoS requirements for the video streaming application should be used by the system. This is because there are some burst profiles share the same SNR range, which requires the system to choose the best one in modulation scheme and coding rate when intended to switch from burst profile to another according to the AMC technique. This is a particular difference between this paper and other papers assuming all the burst profile to be successfully working or assuming only single burst profile. Moreover, it has been noticed that the majority of researches rely on assumptions considered somewhat far from the essentials that characterized the IEEE 802.16e standard.

The overall capacity results show that it is possible to serve up to 24 users simultaneously in FUSC mode and 21 users simultaneously in PUSC mode in the DL subframe after removing the exact calculated overhead messages slots from the total DL subframe slots. Also, the capacity results point out the convergence in the analytical and OPNET simulation results when reaching the maximum number of users for both subcarrier permutation modes.

\section{References:}

[1] J. G. Andrews, A. Ghosh, and R. Muhamed, "Fundamentals of WiMAX Understanding Broadband Wireless Networking”, Prentice Hall Press, 2007.

[2] H. Yaghoobi, "Scalable OFDMA Physical Layer in IEEE 802.16 WirelessMAN," Intel Technology Journal, Vol. 8, No. 3, pp. 201-212, 2004.

[3] WiMAX Forum, "Mobile WiMAX - Part 1: A Technical Overview and Performance Evaluation", August 2006.

[4] L. Nuaymi, "WiMAX: Technology for Broadband Wireless Access", John Wiley and Sons, England, 2007.

[5] A. Kumar, "Mobile Broadcasting with WiMAX: Principles, Technology, and Applications", Elsevier, USA, 2008.

[6] IEEE Std 802.16e-2005, IEEE Std 802. 2004/Cor 1-2005, "IEEE Standard for Local and metropolitan area networks, Part 16: Air Interface for Fixed and Mobile Broadband Wireless Access Systems, Amendment 2: Physical and Medium Access Control Layers for Combined Fixed and Mobile Operation in Licensed Bands and Corrigendum 1.", New York, IEEE, February 28, 2006. 
[7] IEEE Std 802.16" and metropolitan area networks Part 16: Air Interface for Broadband Wireless Access Systems", New York, IEEE, May 29, 2009.

[8] M. Sauter, "Communication Systems for the Mobile Information Society", John Wiley \& Sons, 2006.

[9] B. G. Lee, S. Choi, "Broadband Wireless Access and Local Networks Mobile WiMAX and WiFi", Artech House, USA, 2008.

[10] K. Balachandran, D. Calin, F. Cheng, N. Joshi, J. H. Kang,...., and J. Sun, "Design and Analysis of an IEEE 802.16e-Based OFDMA Communication System," Bell Labs Technical Journal, Vol. 11, No. 4, pp. 53-73, 2007.

[11] Y. S. Cho, J. Kim, W. Y. Yang, C. G. Kang, "MIMO-OFDM Wireless Communications with MATLAB", John Wiley \& Sons, India, 2010.

[12] ITU Document, "Recommendation ITU-R M.1225 - Guidelines for Evaluation of Radio Transmission Technologies for IMT-2000", ITU-R, 1997.

[13] WiMAX Forum, "WiMAX System Evaluation Methodology V2.1,", Jul. 2008.

[14] Y. Gao, L. Chen, X. Zhang and Y. Jiang, "Performance Evaluation of Mobile WiMAX with Dynamic Overhead", IEEE 68th Vehicular Technology Conference (VTC), Calgary Canada, 2008.

[15] A. M. Ahmadzadeh, J. E. Sanchez-García, B. Saavedra-Moreno, A. Portilla-Figueras, "Capacity estimation algorithm for simultaneous support of multi-class traffic services in Mobile WiMAX", Elsevier, Computer Communications Journal, Vol. 35, Issue 1, Pages 109-119, 2012.

[16] D. Pareit, V. Petrov, B. Lannoo, E. Tanghe, W. Joseph, I. Moerman, P. Demeester, L. Martens, "A Throughput Analysis at the MAC Layer of Mobile WiMAX", IEEE Wireless Communications and Networking Conference (WCNC), Sydney, Australia, 18-21 April 2010.

[17] S. E. Abdul Fatah, S. A. Mawjoud, "Mobile WiMAX: System Performance in Terms of Distributed and Adjacent Subcarrier Permutation Modes in ITU-R Vehicular A Channel", IEEE International Conference on Future Communication Networks (ICFCN), Baghdad, pp. 41-46, 2012.

[18] R. Colda, T. Palade, I. Vermeşan, A. Moldovan, E. Puşchiţă, "Link Adaptation in Mobile WiMAX Systems under the ITU-R Mix of Channels", Proceedings of the 14th WSEAS International Conference on COMMUNICATIONS, Corfu Island, Greece, pp. $242-247,2010$.

[19] K. Chen, and J. de Marca, "Mobile WiMAX", John Wiley \& Sons, 2008.

[20] H. Zerrouki, and M. Feham, "High Throughput of WiMAX MIMO-OFDM Including Adaptive Modulation and Coding", International Journal of Computer Science and Information Security, IJCSIS, Vol.7, No.1, pp. 86- 91, 2010, , USA.

[21] I. Tardy, S. Allen, N. K. Elnegaard, S. Hurley, M. Goldhammer,.., R. Taplin, "Planning Guidelines for Broadband Access Networks with Case Studies", BROADWAN Network, May 2006.

[22] A. A. Atayero, O. I. Sheluhin, Y. A. Ivanov, and J. O. Iruemi, "Effect of Wideband Wireless Access Systems Interference Robustness on the Quality of Video Streaming", Proceedings of the World Congress on Engineering and Computer Science (WCECS), Vol II, San Francisco, USA, 2011.

[23] K. Ozdemir, F. Retnasothie, R. Jain, C. So-In, S. Parekh, A. Moskowitz, K. Ramadas, and Mano Vafai, "Triple Play Services including Mobile TV, VoIP, and Internet over Mobile WiMAX Networks", Citeseer, Optimization Journal, pp. 1-14, 2009. 